\title{
Short- and Long-term Effectiveness of Sacral Nerve Stimulation in Patients with Overactive Bladder
}

\author{
Bassam Mahmood Flamerz Arkawazi ${ }^{1}$, Harth Mohamed Kamber ${ }^{2 *}$, Hayder Nabeel Abdulwadoud ${ }^{3}$ \\ ${ }^{1}$ Neurosurgery, Department of Surgery, Division of Neurosurgery, University of Baghdad, Alkindy College of Medicine, Iraq, \\ Baghdad; ' ${ }^{2}$ rology, Department of Surgery, Division of Urology, University of Baghdad, Alkindy College of Medicine, Baghdad, \\ Iraq; ${ }^{3}$ Neurosurgery, Neurosciences Hospital, Baghdad, Iraq
}

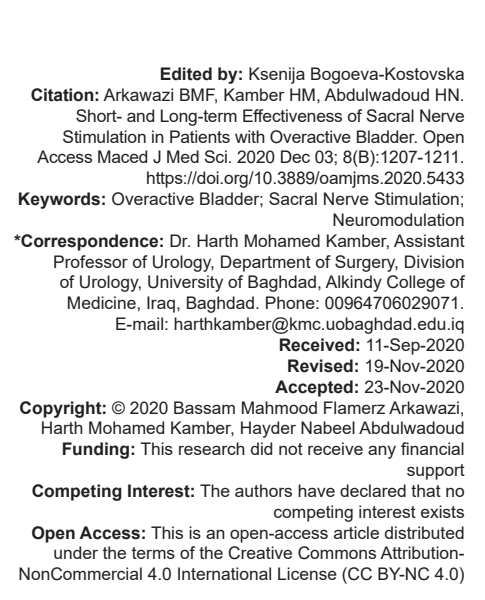

\section{Introduction}

Before the emergence of neuromodulation, Clare Fowler suggested organic etiology for voiding dysfunction in patients with signs of secondary neuroendocrine abnormalities. However, the patients who were complaining of urine retention for many years, regained a spontaneous voiding after a simple test of sacral roots stimulation. This had led to a major reconsideration of the concept of "idiopathic retention" [1], [2].

The results of sacral neuromodulation (SNM) were promising in the nineties of the past century. However, the absence of long-term improvement for some patients led to the questioning of the indications and effectiveness of SNM.

Neurogenic dysfunction is now looked upon as a complex combination of functional abnormalities. Many of these dysfunctions which were considered as "idiopathic" are dealt with now as "non-overt neurogenic." Combinations of pelvic organ dysfunctions, including constipation, voiding dysfunction, sexual dysfunction, urinary retention, fecal incontinence, and/or urinary incontinence, improve with the same treatment modality.
This has led to the realization that the effects of SNM are localized in dealing with sacral symptoms [3].

At least three large randomized controlled trials confirmed the efficacy of implanted sacral neuromodulator for the treatment of patients suffering from severe urgency and urged urinary incontinence. In previous researches, large variation in the clinical profiles, the severity of symptoms, and treatments received before implantation of the implantation of sacral neuromodulator [3].

One of the surgical options for the treatment of bladder dysfunctions involves the implantation of a small device that acts in a way that resembles the action of the pacemaker of the heart in some way. Medtronic developed "InterStim ${ }^{\circledR}$ therapy" which is a method of SNS. This device was approved for use in the United States by the Food and Drug Administration in 1997 [4].

$O A B$ is defined as urinary urgency, usually with urinary frequency and nocturia, with or without urgency urinary incontinence (UUI) [5], [6], [7]. UUI affects more than forty percent of patients with OAB [8]. Whereas among all patients with urinary incontinence about $40-70 \%$ are due to OAB. Most patients with this condition have it for years [9], [10]. 


\section{Aims of the study}

The aim of the study was to assess the shortand long-term effectiveness of SNS in patients with overactive bladder (OAB) regarding age, gender, and causes.

\section{Patients and Method}

This is a clinical prospective cohort study conducted between April 2015 and April 2018 in Ibn Sina hospital and the neurosciences hospital in Baghdad/Iraq. Fifty patients were included in the study, 32 females and 18 males. The age distribution of the patients ranged from 17 to 45 years and patients were divided into two age groups: First group ages from 17 to 30 years and second group ages from 31 to 45 years. All the patients had undergone complete investigations for treatable urological problems, neurological diseases and had been evaluated by a team of neurosurgeons and urologists to evaluate and assess them. Consents were taken from all the patients or their relatives after explaining the surgical technique and the expected outcome and the possible complications for them.

The patients were reevaluated at 6 months postoperatively, as a short-term response follow-up, and 2 years postoperatively as the long-term response follow-up.

\section{study were}

\section{Patients inclusion criteria for the current}

1. Failure to respond to conservative treatment for more than 3 months

2. No concomitant comorbidities

3. Good mentality and intellectual capabilities and cooperation

4. Strict to follow-up periods

5. No treatable causes (urological nor neurological)

6. No urinary outlet obstruction

7. Female patients should not be pregnant

8. Well and healthy site of implantation

9. Succeeded in the temporary phase.

\section{The exclusion criteria were as follows}

1. Pre-pubertal

2. Mixed incontinence (with stress component more than the urge one)

3. Bladder outlet obstruction

4. Agenesis of the sacrum

5. Failure of follow-up

6. Failure to proceed to the permanent phase

7. Pregnant females.
The first step in the patient's management algorithm is that the patient should fill a voiding diary to serve as a baseline record of the patient's clinical response. This is followed by the evaluation of the team. If the team decided to do surgery, the patient would be informed about the successive steps and formal consent was to be filled. Using the Medtronic-InterStim ${ }^{\circledR}$ kit, the procedure then starts by implanting the temporary lead and external pulse generator (EPG). The patient should be in a prone position. The patient was then prepared and draped, exposing both feet and perineum to observe the signs of response on stimulation. Landmarks were set with or without the help of the C-arm. Skin marking and infiltration with local anesthetics solution was followed by insertion of a size 20G, 3.5-inch insulated needle into the S3 foramen on both sides in a vertical orientation in relation to the skin and under the guidance of fluoroscopy to ensure the location and depth of the inserted needle. Electrical stimulation was then applied through the needle to confirm the position of the needle by the observation of gluteal contraction, pelvic floor contraction, with plantiflexion of the big toe. In addition, the awake patient can report a tingling sensation of the pelvic floor. Plantiflexion of the foot with lateral rotation indicates the insertion of the needle in S2 foramen. On the other hand, the absence of lower extremity movement indicates insertion in the S4 foramen. After confirmation of the correct position of the needle, temporary lead wire inserted through the needle before careful removal of the needle to avoid inadvertent dislodgment of the lead. The temporary leads then fixed to the skin by steri-strips and a sterile dressing applied.

The patient then discharged with EPG. The temporary leads could be left for up to 2 months according to the patient's maximum response while the patient completed voiding diaries.

On follow-up period, records were compared and patients were designed as good responders if $\geq 50 \%$ improvement of their complaints. Those would be later candidates for permanent internal pulse generator (IPG) implantation which would be done in the operating room. The patient took the same prone position and the lead was connected to the embedded IPG.

The outcome was assessed according to the following parameters:

1. Number episodes of incontinence in $24 \mathrm{~h}$

2. Number of diapers change in $24 \mathrm{~h}$

3. Severity of incontinence

4. Day-time frequency

5. Nocturnal frequency.

According to the above parameters, the patients were assessed in the short term (6 months) and long term (2 years) in accordance with these parameters and classified as: worse (the episodes or amount of incontinence increase or the frequency increases), no change (no change or the improvement is $<50 \%$ ), good improvement (the episodes and amount of incontinence are $<1 / 2$ half the baseline or if the time between micturition 
is double or more), or very good improvement (when there is full control and the frequency of micturition is $<8$ in a day-time and $<2$ in sleeping time).

The study was approved by the scientific and ethical committee in Al-Kindy College of Medicine University of Baghdad.

\section{Statistical analysis}

Descriptive analysis in the form of percentage was calculated using Microsoft Office Excel Worksheet and presented in the relevant tables shown below. Chisquare test was used for statistical analysis by utilizing the Statistical Package for the Social Sciences (SPSS) version 17 ( $p<0.05$ was considered statistically significant).

\section{Results}

Among the 68 initial candidates for the implantation of the sacral neuromodulator, 50 patients were included in this study (32 female and 18 male) and 18 patients were excluded. Of the excluded patients, 3 patients were pre-pubertal, 6 patients had mixed urinary incontinence with associated internal sphincter deficiency on the urodynamic study, 2 patients refused an operative intervention, 2 patients had uncontrolled diabetes, 2 patients had evidence of bladder outflow obstruction, 1 patient had a positive pregnancy test, and 2 patients were missed from the follow-up.

The results of the age and gender distribution are shown in Table 1.

Table 1: Age and gender distribution of the patients

\begin{tabular}{llll}
\hline Age group & $\begin{array}{l}\text { Female } \\
\text { number }(\%)\end{array}$ & $\begin{array}{l}\text { Male } \\
\text { number }(\%)\end{array}$ & $\begin{array}{l}\text { Total number } \\
(\%)\end{array}$ \\
\hline $1^{\text {st }}$ age group (17-30 years) & $15(30)$ & $10(20)$ & $25(50)$ \\
$2^{\text {nd }}$ age group (31-45 years) & $17(34)$ & $8(16)$ & $25(50)$ \\
\hline
\end{tabular}

At baseline, there was no significant difference between the two age groups and no difference between males and females regarding the frequency of micturition and the number of episodes of incontinence.

On the short- and long-term follow-up, there was no worsening or no change in the condition of our patients.

In female patients, there was a statistically significant better outcome in Group 1 compared to Group 2 ( $p=0.001)$, both on short- and long-term follow-up. The same was found in male patients, $p=0.001$ (Table 2).

Overall, the female patients had better outcomes compared to male patients in the long-term follow-up $(p=0.01)$.

The causes of OAB were idiopathic in 11 $(22 \%)$ patients and neurogenic in $39(78 \%)$ patients.
The neurogenic causes were due to: Spinal cord injury $\mathrm{n}=12(24 \%)$, multiple sclerosis $\mathrm{n}=7(14 \%)$, spinal dysraphism $n=6(12 \%)$, failed back surgery syndrome $n=10(20 \%)$, and other causes $n=4(8 \%)$.

Table 2: Short- and long-term assessment according to age and gender

\begin{tabular}{lllll}
\hline Age and gender follow-up & Worse & $\begin{array}{l}\text { No } \\
\text { change }\end{array}$ & $\begin{array}{l}\text { Good } \\
\text { improvement }\end{array}$ & $\begin{array}{l}\text { Very good } \\
\text { improvement }\end{array}$ \\
\hline Female $(17-30$ years) $n=156$ months & 0 & 0 & 5 & 10 \\
Female $(17-30$ years) $n=152$ years & 0 & 0 & 1 & 14 \\
Female $(31-45$ years) $n=176$ months & 0 & 0 & 12 & 5 \\
Female $(31-45$ years) $n=172$ years & 0 & 0 & 11 & 6 \\
Male $(17-30$ years) $n=106$ months & 0 & 0 & 6 & 4 \\
Male $(17-30$ years) $n=102$ years & 0 & 0 & 4 & 6 \\
Male $(31-45$ years) $n=86$ months & 0 & 0 & 7 & 1 \\
Male $(31-45$ years) $n=82$ years & 0 & 0 & 6 & 2 \\
\hline
\end{tabular}

There was a better outcome in patients with neurogenic causes compared to those with idiopathic causes, which was statistically significant, both on short-term $(p=0.01)$ and long-term $(p=0.005)$ follow-up (Table 3).

Table 3: Short- and long-term assessment according to the cause of overactive bladder

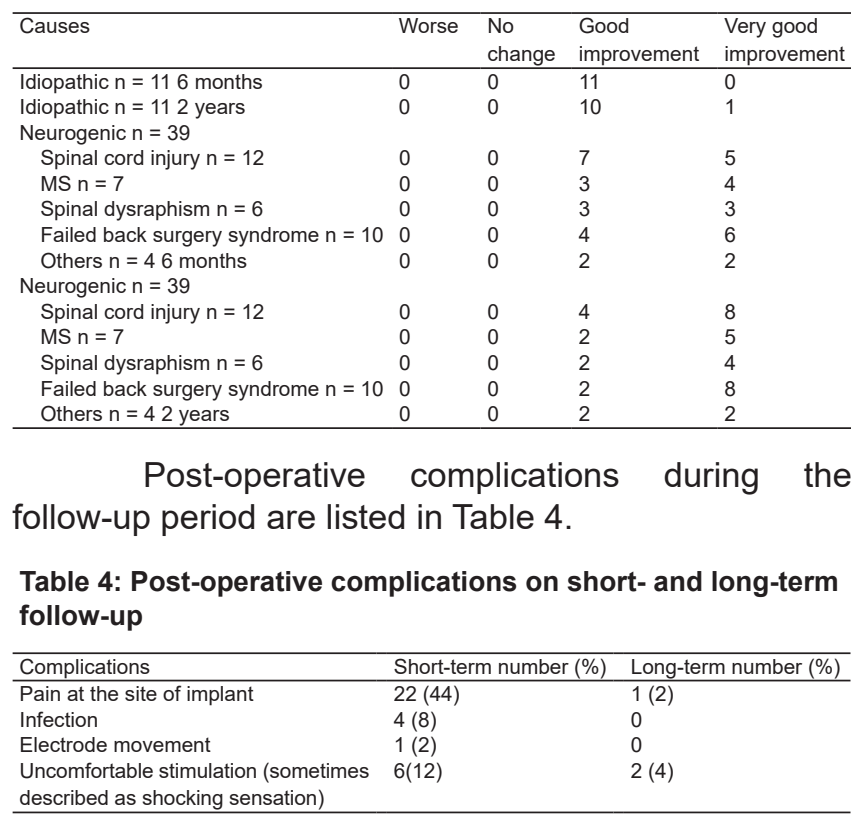

Pain at the site of implantation was treated with simple analgesia, the infection was treated with meticulous dressing and antibiotics, electrode movement was treated by surgical repositioning of the electrode, and the uncomfortable stimulation was tolerable by the patients.

\section{Discussion}

Overall the female patients had better outcomes compared the male patients. The younger age group had a better outcome and the neurogenic cause of OAB also showed better results.

A proportion of patients with OAB improved on standard medical therapy. The main medical treatment 
depends on anticholinergic drugs which reduce the contractility of the bladder muscle (the efferent limb of micturition reflex). Some patients may not respond well to anticholinergic medications. In addition, more than two-thirds of the patients are reluctant to use the medications in the long term due to its side effects or due to incomplete relief of the symptoms. While anticholinergic drugs act at the level of the detrusor muscle, SNM acts at the level of the nerve supply of the bladder to modulate the connection between the bladder and the higher centers controlling the storagevoiding function of the bladder [11].

In this study, female patients did better than male patients, presumably because the number of female patients with $O A B$ was more than the male patients. In addition, the anatomy of the female bladder is less complicated than male bladder and urethra.

Mehmood and Altaweel found that: SNM has demonstrated high rates of clinical success, a significant reduction in voiding-related symptoms, voided volume, and the number of diapers used daily. They also noticed a better female response in the long-term follow-up and neurogenic underlying causes [12]. These are similar to our results.

We also found that the younger age group showed better results and earlier than the older patients. The cause may be due to the unsettlement of the pathological changes as compared to the older patients. This is probably partly due to the shorter duration of the disease at the time of presentation, that is, the severity of the changes can be less, and thus their near-normal anatomy.

Similar long-term data were obtained by Elhilali et al. [3], [4] and Van Voskuilen et al. [13].

White et al. also found that, at a mean follow-up of 40 months, $85.7 \%$ of patients demonstrated a $>50 \%$ improvement in symptoms with SNM and its better in younger patients [10], [14].

Although both patients with neurogenic and idiopathic causes of OAB did improve after the surgery, the neurogenic group showed better responses in both short- and long-term follow-up. This may be explained by the fact that knowing the underlying cause will lead to treating it accordingly, unlike the idiopathic causes that were of unspecified nature.

All our patients underwent the 2 stages technique of SNM. Everaert et al. found that the 2 stages implantation for SNM has a higher success rate than the 1-stage implantation [15], [16].

Datta et al. found that the 2 stages procedure is better than the percutaneous nerve evaluation (PNE) in the restoration of voiding. They further elaborated that of the eight patients with negative PNE results, when they proceeded to the 2 stages procedure, five had voiding restored [13], [17].

\section{Conclusion}

Proper selection of patients is the key to the success of SNS. This study concluded that female patients have better results compared to male patients. Furthermore, younger patients and patients with neurogenic causes did better than older patients and patients with idiopathic causes. Overall, the 2 stages SNS procedure is a safe minimally invasive procedure with a low complication rate.

\section{References}

1. Siegel SW, Catanzaro F, Dijkema HE, Elhilali MM, Fowler CJ, Gajewski JB, et al. Long-term results of a multicenter study on sacral nerve stimulation for treatment of urinary urge incontinence, urgency-frequency, and retention. Urology. 2000;56(6 Suppl 1):87-91. https://doi.org/10.1016/s0090-4295(00)00597-5

PMid:11114569

2. Dmochowski R, Chapple C, Nitti VW, Chancellor M, Everaert K, Thompson C, et al. Efficacy and safety of onabotulinumtoxinA for idiopathic overactive bladder: A double-blind, placebo controlled, randomized, dose ranging trial. J Urol. 2010;184(6):2416-22. https://doi.org/10.1016/j.juro.2010.08.021

PMid:20952013

3. Brazzelli M, Murray A, Fraser C. Efficacy and safety of sacral nerve stimulation for urinary urge incontinence: A systematic review. J Urol. 2006;175(3 Pt 1):835-41. https://doi.org/10.1016/ s0022-5347(05)00326-5

PMid:16469561

4. Bosch JR. An update on sacral neuromodulation: Where do we stand with this in the management of lower urinary tract dysfunction in 2010? BJU Int. 2010;106(10):1432-42. https:// doi.org/10.1111/j.1464-410x.2010.09702.x

PMid:20977592

5. Abrams P, Cardozo L, Fall M, Griffiths D, Rosier P, Ulmsten U, et al. The standardisation of terminology in lower urinary tract function: Report from the standardisation sub-committee of the International Continence Society. Urology. 2003;61(1):37-49. https://doi.org/10.1016/s0090-4295(02)02243-4 PMid:12559262

6. Haylen BT, De Ridder D, Freeman RM, Swift SE, Berghmans B Lee $\mathrm{J}$, et al. An International Urogynecological Association (IUGA)/International Continence Society (ICS) joint report on the terminology for female pelvic floor dysfunction. Neurourol Urodyn. 2010;29(1):4-20. https://doi.org/10.1002/nau.20798 PMid:19941278

7. Drake MJ. Do we need a new definition of the overactive bladder syndrome? ICI-RS 2013. Neurourol Urodyn. 2014;33(5):622-4. https://doi.org/10.1002/nau.22609

PMid:24838519

8. Gibbs RS, Karlan BY, Haney AF, Nygaard IE. Danforth's Obstetrics and Gynecology. Philadelphia, PA: Lippincott Williams and Wilkins; 2008.

9. Habermann TM, Ghosh AK. Mayo Clinic Internal Medicine Concise Textbook. Rochester, MN: CRC Press; 2007. https:// doi.org/10.1201/b14442

10. Kessler TM, Buchser E, Meyer S, Engeler DS, AI-Khodairy AW, Bersch $U$, et al. Sacral neuromodulation for refractory lower 
urinary tract dysfunction: Results of a nationwide registry in Switzerland. Eur Urol. 2007;51(5):1357-63. https://doi. org/10.1016/j.eururo.2006.11.011

PMid:17113216

11. Leong RK, Marcelissen TA, Nieman FH, De Bie RA, Van Kerrebroeck PE, De Wachter SG. Satisfaction and patient experience with sacral neuromodulation: Results of a single center sample survey. J Urol. 2011;185(2):588-92. https://doi. org/10.1016/j.juro.2010.09.090

PMid:21168881

12. Mehmood S, Altaweel WM. Long-term outcome of sacral neuromodulation in patients with idiopathic nonobstructive urinary retention: Single-center experience. Urol Ann. 2017;9(3):244. https://doi.org/10.4103/ua.ua_165_16 PMid:28794590

13. Van Voskuilen A, Oerlemans D, Weil E, De Bie R, Van Kerrebroeck PE. Long term results of neuromodulation by sacral nerve stimulation for lower urinary tract symptoms: A retrospective single center study. Eur Urol. 2006;49(2):366-72. https://doi.org/10.1016/j.eururo.2005.11.009 PMid: 16413105

14. White WM, Mobley III JD, Doggweiler R, Dobmeyer-Dittrich C,
Klein FA. Incidence and predictors of complications with sacral neuromodulation. Urology. 2009;73(4):731-5. https://doi. org/10.1016/j.urology.2008.11.047

PMid:19193415

15. Cameron AP, Anger JT, Madison R, Saigal CS, Clemens JQ, Urologic Diseases in America Project. National trends in the usage and success of sacral nerve test stimulation. J Urol. 2011;185(3):970-5. https://doi.org/10.1016/j.juro.2010.10.060 PMid:21247596

16. Everaert K, Kerckhaert W, Caluwaerts H, Audenaert M, Vereecke $\mathrm{H}$, De Cuypere $\mathrm{G}$, et al. A prospective randomized trial comparing the 1-stage with the 2-stage implantation of a pulse generator in patients with pelvic floor dysfunction selected for sacral nerve stimulation. Eur Urol. 2004;45(5):649-54. https:// doi.org/10.1016/j.eururo.2003.11.015

PMid:15082209

17. Datta SN, Chaliha C, Singh A, Gonzales G, Mishra VC, Kavia RB, et al. Sacral neurostimulation for urinary retention: 10-year experience from one UK centre. BJU Int. 2008;101(2):192-6. https://doi.org/10.1111/j.1464-410x.2007.07282.x

PMid:17970787 